\title{
A model for predicting bacteremia in patients with community-acquired pneumococcal pneumonia: a retrospective observational study
}

\author{
Yasuyoshi Washio ${ }^{1,2^{*}}$, Akihiro Ito $^{2}$, Shogo Kumagai ${ }^{2}$, Tadashi Ishida ${ }^{2}$ and Akio Yamazaki ${ }^{2}$
}

\begin{abstract}
Background: Pneumococcal pneumonia causes high morbidity and mortality among adults. This study aimed to identify risk factors for bacteremic pneumococcal pneumonia, and to construct a prediction model for the development of bacteremia in patients with community-acquired pneumococcal pneumonia.

Methods: We retrospectively analyzed data from patients hospitalized with community-acquired pneumococcal pneumonia between April 2007 and August 2015. Logistic regression models were applied to detect risk factors for pneumococcal bacteremia, and a receiver operating characteristic curve was used to devise a prediction model.

Results: Based on the results of sputum cultures, urine antigen tests, and/or blood cultures, 389 patients were diagnosed with pneumococcal pneumonia, 46 of whom had bacteremia. In the multivariate analysis, age $<65$ years, serum albumin level $<3.0 \mathrm{~g} / \mathrm{dL}$, need for intensive respiratory or vasopressor support (IRVS), and C-reactive protein level $>20 \mathrm{mg} / \mathrm{dL}$ were identified as independent risk factors for the development of pneumococcal bacteremia. The bacteremia prediction score based on receiver operating characteristic curve analysis had a sensitivity of 0.74 and a specificity of 0.78 in patients with two risk factors. The area under the receiver operating characteristic curve was 0.77 ( $95 \%$ confidence interval (Cl), 0.70-0.85).
\end{abstract}

Conclusions: Age < 65 years, hypoalbuminemia, IRVS, and high C-reactive protein level on admission are independent risk factors for the development of bacteremia in patients with community-acquired pneumococcal pneumonia. A prediction model based on these four risk factors could help to identify patients with community-acquired pneumococcal pneumonia at high risk of developing bacteremia; this can be used to guide antibiotic choices.

Trial registration: UMIN-CTR UMIN 000004353. Registered 7 October 2010. Retrospectively registered.

Keywords: Bacteremia, Blood culture, Community-acquired pneumonia, Pneumococcal pneumonia

\section{Background}

Streptococcus pneumoniae is the most common bacterial pathogen and the most frequent cause of death in patients with community-acquired pneumonia (CAP) [1-3]. Gram staining of sputum, sputum culture, blood

\footnotetext{
* Correspondence: yasuyoshiwashio@gmail.com

${ }^{1}$ Department of Respiratory Medicine, Saiseikai Fukuoka General Hospital,

1-3-46 Tenjin, Chuo-ku, Fukuoka 810-0001, Japan

${ }^{2}$ Department of Respiratory Medicine, Ohara Memorial Kurashiki Healthcare

Foundation, Kurashiki Central Hospital, 1-1-1 miwa, Kurashiki, Okayama

710-8602, Japan
}

(c) The Author(s). 2018 Open Access This article is distributed under the terms of the Creative Commons Attribution 4.0 International License (http://creativecommons.org/licenses/by/4.0/), which permits unrestricted use, distribution, and reproduction in any medium, provided you give appropriate credit to the original author(s) and the source, provide a link to the Creative Commons license, and indicate if changes were made. The Creative Commons Public Domain Dedication waiver (http://creativecommons.org/publicdomain/zero/1.0/) applies to the data made available in this article, unless otherwise stated.

culture, and urinary antigen tests are common methods of identifying bacterial pathogens [4]. Antibiotic treatment is prescribed for hospitalized patients on admission. The choice of antibiotic may be empiric or pathogen-directed; the latter based on the results of sputum Gram staining, urinary antigen testing, and other patient characteristics. Although there is no reported difference in outcome between initial pathogen-directed or empiric broad spectrum antibiotic treatment for patients with CAP, pathogen-directed antibiotic treatment based on Gram staining reduces the cost and overuse of 
antibiotics [5, 6]. However, obtaining good quality sputum for Gram staining is often difficult, and sputum culture may lack specificity [7]. Blood culture, because of its high specificity [8], is an important means of identifying pathogens causing pneumonia and for predicting clinical outcomes. In patients with CAP, the development of bacteremia or septic shock is associated with increased risk of mortality $[9,10]$.

Given that blood culture results are usually not available until several days after admission, a model predicting bacteremia would be a useful tool for anticipating a patient's clinical course and for choosing appropriate antibiotic treatment. Metersky et al. [11] reported an association between bacteremic pneumonia and vital signs, liver disease, and laboratory findings on admission in patients with CAP. Previously reported risks factors for bacteremic pneumococcal CAP are smoking, the use of immunosuppressive drugs, younger age, and the presence of diabetes mellitus [12]. Regarding antibiotic treatment for bacteremic pneumococcal pneumonia, the in-hospital mortality rate is lower in patients treated with a beta-lactam plus a macrolide than in those treated with beta-lactam monotherapy [13].

Despite their usefulness, existing models for predicting bacteremia in patients with CAP can be complicated to apply in the clinical setting, where patient populations and pathogens are non-uniform [14, 15]. Moreover, there are no existing models for predicting bacteremia in pneumococcal CAP, specifically. In this study, we aimed to identify risk factors associated with bacteremia and to construct a model to predict bacteremia in patients with pneumococcal CAP. Such a model may help clinicians to decide on the most appropriate antibiotic treatment to initiate on admission, including whether or not to use combination therapy.

\section{Methods}

\section{Study design and setting}

We retrospectively analyzed the data of all patients hospitalized for pneumococcal CAP and enrolled in a prospective observational cohort study at Kurashiki Central Hospital, Okayama, Japan, between April 2007 and August 2015. Pneumonia was diagnosed based radiographic findings (new infiltrates compatible with a diagnosis of pneumonia on chest $\mathrm{x}$-ray) and clinical findings (acute-onset clinical symptoms suggestive of a lower respiratory tract infection, such as cough, sputum production, fever, pleural chest pain, or dyspnea). Chest $x$-ray images demonstrating new infiltrates were assessed by two or more respiratory medicine clinicians. Patients aged $\leq 15$ years and those with immunosuppression or hospital-acquired or healthcare-associated pneumonia, were excluded. Included patients were divided into two groups; one with bacteremia and the other without. This study was approved by the institutional review board of Kurashiki Central Hospital (approval number 2235). Based on the Ethical Guidelines for Medical and Health Research Involving Human Subjects of the Ministry of Health, Labour and Welfare, we notify the research subjects of, or make public, information concerning the research in our hospital. All patients gave their informed consent to participate in this study by being given opportunities to refuse to participate.

\section{Clinical characteristics}

The severity of pneumonia was assessed for all patients on admission using the CURB-65 score (a severity score based on confusion, blood urea nitrogen (BUN) levels, respiratory rate, blood pressure, and age), the Pneumonia Severity Index score, or the Infectious Diseases Society of America (IDSA)/American Thoracic Society (ATS) criteria for severe CAP [16-18].

The following patient data were recorded: age, sex, smoking status, high alcohol consumption (defined as consuming $\geq 5$ alcoholic drinks per day for $>10$ years), multilobar pneumonia, previous antibiotic treatment, corticosteroid use before hospitalization, Eastern Cooperative Oncology Group (ECOG) performance status score (0: normal activity, 1: some symptoms, but no bed rest during daytime, 2: bed rest for less than 50\% of daytime, 3: bed rest for more than 50\% of daytime, 4: unable to get out of bed), and underlying diseases (chronic obstructive pulmonary disease, bronchial asthma, chronic cardiovascular disease, cerebrovascular disease, chronic renal disease, chronic liver disease, malignant disease, and/or diabetes mellitus). In addition, vital signs at the time of arrival, laboratory findings (concentrations of blood glucose and BUN; serum albumin, C-reactive protein (CRP), and sodium concentrations; hematocrit; and partial pressure arterial oxygen/ fraction of inspired oxygen $(\mathrm{PaO} 2 / \mathrm{FiO} 2)$ ratio) and diagnostic methods, were recorded. We recorded admission intensive care unit (ICU), vasopressor drug use, mechanical ventilation, and intensive respiratory or vasopressor support (IRVS; i.e., invasive or noninvasive mechanical ventilation or infusion of vasopressors for blood pressure support [19]).

Pneumococcal CAP was defined as at least one positive result for Streptococcus pneumoniae on blood, sputum, tracheal bronchial aspirate, and/or urinary antigen testing using the BinaxNOW ${ }^{\circ}$ Streptococcus pneumoniae Antigen Card (Alere Inc., Waltham, MA, USA) in a patient with clinical and radiographic features of CAP. Sputum specimens with $>25$ leucocytes per field were considered of sufficient quality for diagnosis. Bacteremic pneumococcal pneumonia was diagnosed on the basis of isolating S. pneumoniae from blood cultures 
obtained before the parenteral administration of antibiotics.

\begin{abstract}
Analysis
Fisher's exact test and the non-parametric MannWhitney $U$ test were used to detect significant differences in categorical and continuous variables, respectively, between the two groups. Univariate and multivariate logistic regression analyses were performed to identify variables predictive of pneumococcal bacteremia development. Variables with a $p$-value $<0.05$ in the univariate analysis were included in the multivariate logistic regression models using a stepwise approach. Cut-off values for these variables were obtained from previous studies [11, 15, 18, 20, 21]. Receiver operating characteristic (ROC) curves were constructed to predict the development of pneumococcal bacteremia based on factors detected in the multivariate analysis. All statistical tests were two-tailed, and a $p$-value $<0.05$ was considered significant. Analyses were conducted using $\mathrm{R}$ statistical software (version 3.4.1, Vienna, Austria).
\end{abstract}

\section{Results}

Of 1829 patients hospitalized with CAP during the study period, 389 (21.3\%) were diagnosed with pneumococcal pneumonia. Of these, 46 (12\%) had concomitant bacteremia (bacteremic group) and 343 (88\%) did not (non-bacteremic group). The baseline characteristics of both groups are listed in Table 1. The following were found more frequently in the bacteremic than in the non-bacteremic group: Age $<65$ years, vasopressor use, mechanical ventilation, IRVS, and an increased number of ATS/IDSA severe criteria.

Patients in the bacteremic group also had higher respiratory and heart rates, lower serum albumin levels, higher BUN and CRP levels, lower serum sodium concentrations, and lower $\mathrm{PaO} 2 / \mathrm{FiO} 2$ ratios. There were no significant differences between the two groups regarding underlying disease, sex, smoking status, high alcohol consumption, previous antibiotic treatment, corticosteroid treatment before hospitalization, multilobar pneumonia, level of consciousness, method of diagnosis of pneumococcal pneumonia, ECOG performance status, or pneumonia severity indices.

The univariate logistic regression analysis revealed that age $<65$ years, respiratory rate $>30$ breaths $/ \mathrm{min}$, heart rate $>125$ beats/min, IRVS, albumin $<3.0 \mathrm{mg} / \mathrm{dL}$, BUN $>30 \mathrm{mg} / \mathrm{dL}$, serum sodium $<130 \mathrm{mEq} / \mathrm{L}$, and CRP > $20 \mathrm{mg} / \mathrm{dL}$ were associated with increased odds of pneumococcal bacteremia. The multivariate analysis identified age $<65$ years, IRVS, albumin $<3.0 \mathrm{mg} / \mathrm{dL}$, and CRP $>20 \mathrm{mg} / \mathrm{dL}$ as being independent risk factors for pneumococcal bacteremia (Table 2). We devised a predictive score using these four factors, allocating one point to each factor. The area under the ROC curve was 0.77 (95\% confidence interval (CI), 0.70-0.85) with 0.74 sensitivity and 0.78 specificity for patients with two points (Fig. 1). Only 5\% (13/277) of patients with 0 or 1 point had bacteremia, whereas all patients with 4 points had bacteremia (Fig. 2, Table 3).

\section{Discussion}

The main finding of this study is that age $<65$ years, IRVS, hypoalbuminemia, and elevated CRP levels were identified as risk factors for pneumococcal bacteremia in patients with pneumococcal CAP. Our prediction model using these four risk factors is the first system exclusively designed to identify pneumococcal bacteremia in patients with pneumococcal CAP. Previous studies investigating bacteremia in patients with pneumonia identified different risk factors. This discrepancy is due to the heterogeneity in causative pathogens or study cohorts; for example, some studies included patients with pneumonia irrespective of etiology while others included only patients with CAP $[9,10,12,20,22,23]$. Our study is important as our sample was limited to patients with pneumococcal CAP. Although Amaro et al. [21] reported on risk factors for bacteremia in patients with pneumococcal CAP, there is still a paucity of information on this topic, and there is currently no specific prediction model.

Younger age has been reported to be a significant and independent risk factor for bacteremia in patients with CAP [12, 20, 24]; our findings concur with this. However, it is not clear why younger patients are at greater risk of bacteremia; pneumococcal vaccination and the serotype of S. pneumoniae may play a role. In Japan, the 13 -valent pneumococcal conjugate vaccine was approved for use as a voluntary vaccine for adults aged $\geq 65$ years in June 2014. The 23-valent pneumococcal polysaccharide vaccine was approved for use in 1988 and routine immunization for those aged $\geq 65$ years was introduced in October 2014. These pneumococcal vaccines are recommended for adults aged $\geq 65$ years to prevent pneumonia and other invasive pneumococcal diseases, and to improve clinical outcomes $[25,26]$. Because the rate of vaccination increases depending on age and younger adults usually don't take pneumococcal vaccines, this may have led to younger age being identified as a risk factor for bacteremia [27]. Moreover, S. pneumoniae serotype 1 is the most commonly isolated serotype in invasive pneumococcal disease; it is more likely than the other serotypes to be identified in young patients without comorbidities [28]. The results from this study suggest a relationship between the pneumococcal serotype and study population with bacteremia; however, a 
Table 1 Characteristics of patients hospitalized with bacteremic and non-bacteremic community-acquired pneumococcal pneumonia

\begin{tabular}{|c|c|c|c|c|}
\hline Characteristic & Category & No bacteremia $(n=343)$ & Bacteremia $(n=46)$ & $p$ value \\
\hline \multirow[t]{4}{*}{ Demographic characteristics } & Age (years), median (range) & 77 (20-97) & $68(29-91)$ & $0.001^{a}$ \\
\hline & Female sex & $119(34.7)$ & $15(32.6)$ & 0.87 \\
\hline & Current smoker & $53(15.5)$ & $9(19.6)$ & 0.52 \\
\hline & High alcohol consumption & $9(2.6)$ & $3(6.5)$ & 0.16 \\
\hline \multirow[t]{9}{*}{ Underlying disease(s) } & Chronic cardiovascular disease & $92(26.8)$ & $8(17.4)$ & 0.21 \\
\hline & COPD & $86(25.1)$ & $10(21.7)$ & 0.72 \\
\hline & Bronchial asthma & $62(18.1)$ & $6(13.0)$ & 0.54 \\
\hline & Diabetes mellitus & $53(15.5)$ & $7(15.2)$ & 1.00 \\
\hline & Chronic liver disease & $17(5.0)$ & $3(6.5)$ & 0.79 \\
\hline & Chronic renal disease & $27(7.9)$ & $3(6.5)$ & 1.00 \\
\hline & Malignant disease & $33(9.6)$ & $5(10.9)$ & 0.79 \\
\hline & Cerebrovascular disease & $70(20.4)$ & $6(13.0)$ & 0.32 \\
\hline & Previous antibiotic treatment & $69(20.1)$ & $6(13.0)$ & 0.32 \\
\hline $\begin{array}{l}\text { Corticosteroid use } \\
\text { before hospitalization }\end{array}$ & Yes & $3(0.9)$ & $0(0.0)$ & 1.00 \\
\hline \multirow{6}{*}{$\begin{array}{l}\text { Clinical characteristics } \\
\text { on admission }\end{array}$} & Temperature $\left({ }^{\circ} \mathrm{C}\right)$ & $38.2(34.4-40.9)$ & $38.1(34.3-40.0)$ & 0.63 \\
\hline & Respiratory rate (breaths. $\mathrm{min}^{-1}$ ) & $24(10-60)$ & $26(10-50)$ & $0.005^{a}$ \\
\hline & Heart rate (beats.min ${ }^{-1}$ ) & $100(52-173)$ & $109(78-163)$ & $0.002^{\mathrm{a}}$ \\
\hline & Systolic blood pressure (mmHg) & $128(30-226)$ & $123(65-191)$ & 0.36 \\
\hline & Impaired consciousness & $63(18.4)$ & $9(19.6)$ & 0.84 \\
\hline & Multilobar pneumonia & $209(60.9)$ & $33(71.7)$ & 0.20 \\
\hline \multirow[t]{7}{*}{ Laboratory findings } & Serum albumin $\left(\mathrm{mg} \cdot \mathrm{dL}^{-1}\right)$ & $3.4(1.5-4.8)$ & $2.7(0.5-4.3)$ & $<0.001^{\mathrm{a}}$ \\
\hline & BUN $\left(m g \cdot d L^{-1}\right)$ & $20(4-161)$ & $26(11-105)$ & $0.002^{\mathrm{a}}$ \\
\hline & Blood glucose $\left(\mathrm{mg} \cdot \mathrm{dL}^{-1}\right)$ & $133(66-517)$ & $130(61-413)$ & 0.76 \\
\hline & Serum CRP $\left(\mathrm{mg} \cdot \mathrm{L}^{-1}\right)$ & $12.5(0.07-48.6)$ & $24.9(0.55-51.1)$ & $<0.001^{\mathrm{a}}$ \\
\hline & Hematocrit (\%) & $37.6(20.3-54.2)$ & $36.0(25.0-51.9)$ & 0.67 \\
\hline & Sodium (mEq. $\mathrm{L}^{-1}$ ) & $137(111-150)$ & $135(129-146)$ & $0.03^{\mathrm{a}}$ \\
\hline & $\mathrm{P} / \mathrm{F}$ ratio & $248(35.7-512)$ & $197(35.7-420)$ & $0.01^{\mathrm{a}}$ \\
\hline \multirow[t]{4}{*}{ Microbiologic diagnosis } & Sputum Gram stain & $89(25.9)$ & $12(26.7)$ & 1.00 \\
\hline & Sputum culture & $244(71.1)$ & $32(69.6)$ & 0.86 \\
\hline & Urinary antigen test & $200(61.0)$ & $37(76.1)$ & 0.05 \\
\hline & Sputum culture and urinary antigen test & $109(31.8)$ & $21(45.7)$ & 0.07 \\
\hline \multirow[t]{5}{*}{ ECOG performance status } & 0 & $54(21.2)$ & $12(46.2)$ & 0.07 \\
\hline & 1 & $112(43.9)$ & $10(38.5)$ & \\
\hline & 2 & $50(19.6)$ & $2(7.7)$ & \\
\hline & 3 & $24(9.4)$ & $2(7.7)$ & \\
\hline & 4 & $15(5.9)$ & $0(0)$ & \\
\hline \multirow[t]{6}{*}{ CURB-65 class } & 0 & $32(9.3)$ & $4(8.9)$ & 0.12 \\
\hline & 1 & $86(25.1)$ & $10(22.2)$ & \\
\hline & 2 & $127(37.0)$ & $10(22.2)$ & \\
\hline & 3 & $67(19.5)$ & $14(31.1)$ & \\
\hline & 4 & $26(7.6)$ & $5(11.1)$ & \\
\hline & 5 & $5(1.5)$ & $2(4.4)$ & \\
\hline PSI class & । & $7(2.0)$ & $1(2.2)$ & 0.37 \\
\hline
\end{tabular}


Table 1 Characteristics of patients hospitalized with bacteremic and non-bacteremic community-acquired pneumococcal pneumonia (Continued)

\begin{tabular}{|c|c|c|c|c|}
\hline Characteristic & Category & No bacteremia $(n=343)$ & Bacteremia $(n=46)$ & $p$ value \\
\hline & $\|$ & $34(9.9)$ & $5(10.9)$ & \\
\hline & III & $80(23.4)$ & $12(26.1)$ & \\
\hline & IV & $150(43.9)$ & $14(30.4)$ & \\
\hline & V & $71(20.8)$ & $14(20.4)$ & \\
\hline IDSA/ATS severe & & $120(35.0)$ & $29(63.0)$ & $<0.001^{\circ}$ \\
\hline ICU admission & Yes & $16(4.7)$ & $11(23.9)$ & $<0.001^{\mathrm{c}}$ \\
\hline Vasopressor use & Yes & $14(4.1)$ & $10(21.7)$ & $<0.001^{\circ}$ \\
\hline $\begin{array}{l}\text { Invasive or noninvasive } \\
\text { mechanical ventilation }\end{array}$ & Yes & $18(5.2)$ & $12(26.1)$ & $<0.001^{\circ}$ \\
\hline IRVS & Yes & $20(5.8)$ & $13(28.3)$ & $<0.001^{\circ}$ \\
\hline
\end{tabular}

adenotes significant value

Abbreviations: COPD chronic obstructive pulmonary disease, IRVS intensive respiratory or vasopressor support, ICU intensive care unit, ECOG Eastern Cooperative Oncology Group, CURB-65 confusion, urea $>7 \mathrm{mmol} \cdot \mathrm{L}^{-1}$, respiratory rate $\geq 30$ breaths. $\mathrm{min}^{-1}$, low blood pressure (systolic $<90 \mathrm{mmHg}$ or diastolic $\leq 60 \mathrm{mmHg}$ ) and age $\geq 65$ y, PSI Pneumonia Severity Index, IDSA Infectious Diseases Society of America, ATS American Thoracic Society, BUN blood urea nitrogen, CRP C-reactive protein, $P / F$ ratio $\mathrm{PaO}_{2} / \mathrm{FiO}_{2}$ ratio

limitation of our study was that we did not collect information on serotype, so this relationship could not be assessed.

Previous studies have shown low serum albumin or high serum CRP concentrations to be risk factors for bacteremia in patients with CAP $[15,20,21,29]$; our findings are consistent with this. Low serum albumin concentration is a risk factor for and a predictor of morbidity and mortality, regardless of the disease [30], and a relationship exists between hypoalbuminemia and severe infection due to the elevation of cytokine levels during systemic inflammation [31]. Hypoalbuminemia, an elevated inflammatory response, or both, results in worse clinical outcomes for patients with severe infection.

Capelastegui et al. [10] reported that patients with pneumococcal bacteremia had a higher frequency of requiring mechanical ventilation and treatment for septic shock with vasopressor drugs than did non-bacteremic patients, but there was no difference in the rate of ICU admission. In contrast, in the present study, a greater proportion of patients in the bacteremic group than in the non-bacteremic group required vasopressors, mechanical ventilation, and ICU admission. This discrepancy may be due to differences in the criteria used for ICU admission between hospitals and countries. Then we chose the need for IRVS-and for vasopressor drugs, in particular-, which is a more objective marker of CAP severity than is simple ICU admission [19]. Although previous studies have reported that low systolic blood pressure is a risk factor for bacteremia [20,24], this was not identified as a significant risk factor in the present study; however, the use of vasopressors was. This may have been influenced by clinicians' choice of vasopressors that provide direct $\beta 1$ stimulation (such as

Table 2 Univariate and multivariate analyses showing potential risk factors for bacteremia in community-acquired pneumococcal pneumonia

\begin{tabular}{|c|c|c|c|c|}
\hline \multirow[t]{2}{*}{ Variable } & \multicolumn{2}{|c|}{ Univariate analysis } & \multicolumn{2}{|c|}{ Multivariate analysis } \\
\hline & OR $(95 \% \mathrm{Cl})$ & $p$-value & OR $(95 \% \mathrm{Cl})$ & $p$-value \\
\hline Age $<65$ years & $3.00(1.55-5.83)$ & $0.006^{\mathrm{a}}$ & $3.64(1.73-7.67)$ & $<0.001^{\mathrm{a}}$ \\
\hline Respiratory rate $>30$ breaths $\cdot \mathrm{min}^{-1}$ & $2.65(1.39-5.03)$ & $0.003^{\mathrm{a}}$ & & \\
\hline Heart rate $>125$ beats. $\mathrm{min}^{-1}$ & $2.44(1.12-5.35)$ & $0.03^{\mathrm{a}}$ & & \\
\hline IRVS & $6.36(2.90-13.9)$ & $<0.001^{a}$ & $3.99(1.71-9.33)$ & $0.001^{\mathrm{a}}$ \\
\hline Serum albumin $<3.0 \mathrm{mg} \cdot \mathrm{dL}^{-1}$ & $4.18(2.21-7.92)$ & $<0.001^{\mathrm{a}}$ & $3.35(1.63-6.87)$ & $0.001^{\mathrm{a}}$ \\
\hline $\mathrm{BUN}>30 \mathrm{mg} \cdot \mathrm{dL}^{-1}$ & $1.87(0.97-3.57)$ & 0.06 & & \\
\hline Serum sodium $<130 \mathrm{mEq} \cdot \mathrm{L}^{-1}$ & $3.10(1.05-9.13)$ & $0.04^{\mathrm{a}}$ & & \\
\hline $\mathrm{P} / \mathrm{F}$ ratio $<250$ & $2.57(1.36-4.85)$ & $0.004^{\mathrm{a}}$ & & \\
\hline Serum CRP $>20 \mathrm{mg} \cdot \mathrm{dL}^{-1}$ & $4.12(2.18-7.77)$ & $<0.001^{\mathrm{a}}$ & $2.39(1.21-4.75)$ & $0.01^{\mathrm{a}}$ \\
\hline
\end{tabular}

denotes significant value

Abbreviations: $O R$ odds ratio, $\mathrm{Cl}$ confidence interval, $\mathrm{BUN}$ blood urea nitrogen, $\mathrm{P} / \mathrm{F}$ ratio $\mathrm{PaO}_{2} / \mathrm{FiO}_{2}$ ratio, $C R P \mathrm{C}$-reactive protein, IRVS intensive respiratory or vasopressor support 


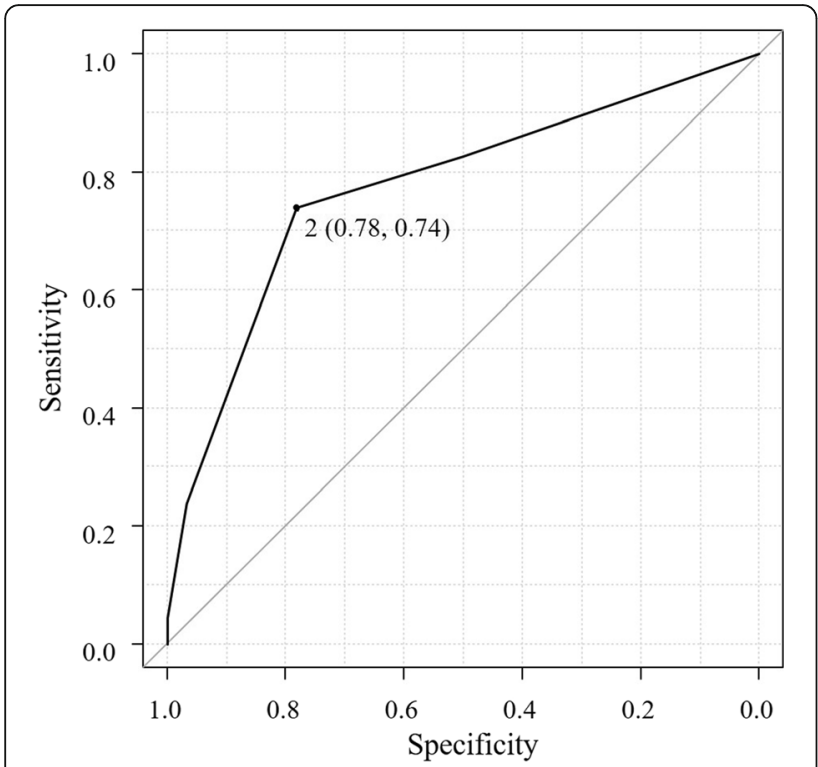

Fig. 1 Receiver-operating characteristic curve for four factors predictive of bacteremia in community-acquired pneumococcal pneumonia patients. Area under the curve $=0.77$ (95\% confidence interval, 0.70-0.85). The four factors predictive of bacteremia were age $<65$ years, albumin level $<3.0 \mathrm{~g} / \mathrm{dL}$, need for intensive respiratory or vasopressor support, and C-reactive protein level $>20 \mathrm{mg} / \mathrm{dL}$. Each factor was allocated one point in the prediction model. For patients scoring two points, the specificity was 0.78 and sensitivity was 0.74

dobutamine) for cardiac dysfunction in patients with invasive pneumococcal disease.

Patients with pneumococcal pneumonia or sepsis are at increased risk of a concurrent acute cardiac event (myocardial infarction, arrhythmia, or new or worsening

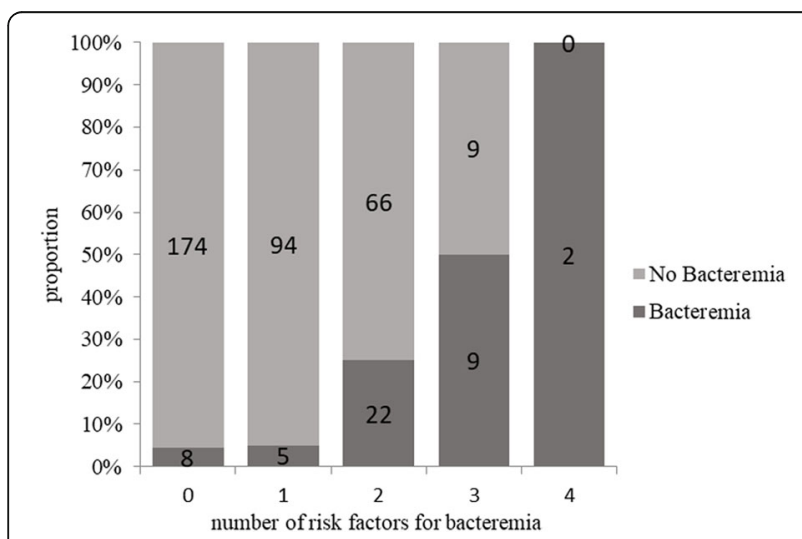

Fig. 2 Proportion of patients with community-acquired pneumococcal pneumonia according to bacteremia prediction model score. Four significant risk factors for bacteremia in community-acquired pneumococcal pneumonia patients were identified (age < 65 years, albumin level $<3.0 \mathrm{~g} / \mathrm{dL}$, need for intensive respiratory or vasopressor support, and C-reactive protein level $>20 \mathrm{mg} / \mathrm{dL}$ ). Each risk factor was allocated one point in the bacteremia prediction model. The figure shows the proportion of patients with $0,1,2,3$, and 4 risk factors with and without bacteremia
Table 3 Accuracy of the diagnostic score according to the number of risk factors for bacteremia

\begin{tabular}{lllll}
\hline $\begin{array}{l}\text { Number of risk } \\
\text { factors }\end{array}$ & Bacteremia & $\begin{array}{l}\text { No } \\
\text { Bacteremia }\end{array}$ & Sensitivity & Specificity \\
\hline 0 & $8(17.4 \%)$ & $174(50.7 \%)$ & 1.00 & - \\
$\geq 1$ & $38(82.6 \%)$ & $169(49.3 \%)$ & 0.83 & 0.50 \\
$\geq 2$ & $33(71.7 \%)$ & $75(21.9 \%)$ & 0.74 & 0.78 \\
$\geq 3$ & $11(23.9 \%)$ & $9(2.6 \%)$ & 0.24 & 0.97 \\
4 & $2(4.3 \%)$ & 0 & 0.043 & 1.00 \\
\hline
\end{tabular}

congestive heart failure caused by suppression of ventricular function) due to the severe inflammatory response and elevated levels of cytokines triggered by the use of antibiotics, which rapidly increases the release of bacterial cell wall fragments into the blood stream $[32,33]$. In vitro, platelet activating factor receptors facilitate the binding of circulating $S$. pneumoniae bacterial cell walls to endothelial cells, bacterial entry into organs, and specific uptake into non-phagocytic cells such as cardiomyocytes [34]. In a non-human primate model, Reyes et al. [35] reported that S. pneumoniae can invade the blood stream and the myocardium, inducing severe cardiac injury with necroptosis and apoptosis, and disrupting cardiac function; notably, such injury occurred despite the use of antibiotics.

Previous studies involving patients with bacteremic pneumococcal CAP have considered prediction models relating to CAP $[11,15,20]$. Our prediction model is the first and only available model to predict pneumococcal bacteremia specifically. In our study, very few patients who scored 0 or 1 point developed pneumococcal bacteremia, whereas all patients who scored 4 points did. This prediction model can help clinicians to decide on the best antibiotic choice. Regarding treatment, combination therapy with a beta-lactam plus a macrolide is prescribed empirically for patients with CAP because of the possibility of infection with an atypical pathogen. Combination therapy is contraindicated in some patients because of the adverse effects of macrolides, including arrhythmias, and the possibility that frequent use of macrolides will lead to antibiotic resistance. It is unclear whether this combination is useful for all patients with CAP. Douwe et al. [36] reported no difference in 90-day mortality between patients with CAP treated with a beta-lactam alone, a beta-lactam plus a macrolide, or quinolone alone. However, some studies have reported that combination therapy does improve outcomes for patients with bacteremic pneumococcal CAP or for severely ill patients with pneumococcal bacteremia [13, 37]. Clinicians need to choose whether to use combination therapy days before blood culture results are available. By using our prediction model to identify patients (diagnosed with pneumococcal CAP by Gram 
stain or urinary antigen testing) at high risk of developing bacteremia, the beneficial effects of combination therapy could be maximized-thereby improving outcomes-while minimizing adverse events.

This study has several limitations. First, it was a small, retrospective study, and all patients were selected from a single treatment center. Second, although vaccination against $S$. pneumoniae may reduce the severity of pneumococcal infection or invasive disease and the $S$. pneumoniae serotype may have influenced the occurrence of bacteremia in this study population, neither vaccination status nor S. pneumoniae serotype were included as potential risk factors in our analysis. Hence, further cohort studies are needed to verify potential risk factors and validate the performance of our model for predicting pneumococcal bacteremia.

Notwithstanding these limitations, our prediction model is based on easily identifiable risk factors, is simple to use, and provides an effective method for clinicians to identify patients at risk of developing bacteremia.

\section{Conclusions}

Our findings indicate that age $<65$ years, hypoalbuminemia, need for IVRS, and high serum CRP levels on admission are independent risk factors for the development of bacteremia in patients with pneumococcal CAP. Our prediction model, based on these four risk factors, may be helpful in treatment guiding decisions-specifically whether initial antibiotic therapy should include combination antibiotic therapy with a beta-lactam plus a macrolide, which is associated with better outcomes in this population.

\section{Abbreviations}

ATS: American Thoracic Society; BUN: Blood urea nitrogen;

CAP: Community-acquired pneumonia; CRP: C-reactive protein;

ECOG: Eastern Cooperative Oncology Group; IDSA: Infectious Diseases

Society of America; PSI: Pneumonia Severity Index; ROC: Receiver operating characteristic

\section{Acknowledgements}

The authors would like to thank all their colleagues who recruited and treated patients with CAP.

\section{Funding}

No financial support was received for this study.

\section{Availability of data and materials}

The datasets used and analyzed during the current study are available from the corresponding author upon request.

\section{Authors' contributions}

YW served as the principal author, had full access to all data in the study, and takes responsibility for the integrity and accuracy of the data and data analysis. YW, Al and SK contributed to the study conception and design; YW, $\mathrm{Al}, \mathrm{TI}$ and $\mathrm{AY}$ contributed to the acquisition of data; $\mathrm{YW}, \mathrm{Al}, \mathrm{TI}$ and $\mathrm{AY}$ contributed to the analysis and interpretation of data; YW and Al contributed to the drafting and revision of the manuscript and all authors read and approved the final version for publication.

\section{Ethics approval and consent to participate}

This study was approved by the institutional review board of Kurashiki Central Hospital (approval number 2235). All patients provided informed consent to participate in this study.

\section{Consent for publication}

Not applicable.

\section{Competing interests}

TI has received honoraria from Pfizer, Japan, Inc. The other authors declare that they have no competing interests.

\section{Publisher's Note}

Springer Nature remains neutral with regard to jurisdictional claims in published maps and institutional affiliations.

Received: 12 July 2017 Accepted: 4 January 2018

Published online: 30 January 2018

\section{References}

1. Ardanuy C, Tubau F, Pallares R, Calatayud L, Dominguez MA, Rolo D, et al. Epidemiology of invasive pneumococcal disease among adult patients in barcelona before and after pediatric 7-valent pneumococcal conjugate vaccine introduction, 1997-2007. Clin Infect Dis. 2009;48:57-64.

2. Roson B, Carratala J, Dorca J, Casanova A, Manresa F, Gudiol F. Etiology, reasons for hospitalization, risk classes, and outcomes of communityacquired pneumonia in patients hospitalized on the basis of conventional admission criteria. Clin Infect Dis. 2001;33:158-65.

3. Shariatzadeh MR, Huang JQ, Tyrrell GJ, Johnson MM, Marrie TJ. Bacteremic pneumococcal pneumonia: a prospective study in Edmonton and neighboring municipalities. Medicine (Baltimore). 2005;84:147-61.

4. Bartlett JG. Diagnostic tests for agents of community-acquired pneumonia. Clin Infect Dis. 2011;52(Suppl 4):S296-304.

5. van der Eerden MM, Vlaspolder F, de Graaff CS, Groot T, Bronsveld W, Jansen $\mathrm{HM}$, et al. Comparison between pathogen directed antibiotic treatment and empirical broad spectrum antibiotic treatment in patients with community acquired pneumonia: a prospective randomised study. Thorax. 2005:60:672-8

6. Taniguchi T, Tsuha S, Shiiki S, Narita M. Gram-stain-based antimicrobial selection reduces cost and overuse compared with Japanese guidelines. BMC Infect Dis. 2015;15:458.

7. Skerrett SJ. Diagnostic testing to establish a microbial cause is helpful in the management of community-acquired pneumonia. Semin Respir Infect. 1997;12:308-21.

8. Luna CM, Famiglietti A, Absi R, Videla AJ, Nogueira FJ, Fuenzalida AD, et al. Community-acquired pneumonia: etiology, epidemiology, and outcome at a teaching hospital in Argentina. Chest. 2000;118:1344-54.

9. Garcia-Vidal C, Ardanuy C, Tubau F, Viasus D, Dorca J, Linares J, et al. Pneumococcal pneumonia presenting with septic shock: host- and pathogen-related factors and outcomes. Thorax. 2010;65:77-81.

10. Capelastegui A, Zalacain R, Bilbao A, Egurrola M, Iturriaga LA, Quintana JM, et al. Pneumococcal pneumonia: differences according to blood culture results. BMC Pulm Med. 2014;14:128.

11. Metersky ML, Ma A, Bratzler DW, Houck PM. Predicting bacteremia in patients with community-acquired pneumonia. Am J Respir Crit Care Med. 2004;169:342-7.

12. Kang Cl, Song JH, Kim SH, Chung DR, Peck KR, Thamlikitkul V, et al. Risk factors and pathogenic significance of bacteremic pneumonia in adult patients with community-acquired pneumococcal pneumonia. J Inf Secur. 2013:66:34-40.

13. Martinez JA, Horcajada JP, Almela M, Marco F, Soriano A, Garcia E, et al. Addition of a macrolide to a beta-lactam-based empirical antibiotic regimen is associated with lower in-hospital mortality for patients with bacteremic pneumococcal pneumonia. Clin Infect Dis. 2003;36:389-95.

14. Falquera M, Trujillano J, Caro S, Menendez R, Carratala J, Ruiz-Gonzalez A, et al. A prediction rule for estimating the risk of bacteremia in patients with community-acquired pneumonia. Clin Infect Dis. 2009:49:409-16.

15. Lee J, Hwang SS, Kim K, Jo YH, Lee JH, Kim J, et al. Bacteremia prediction model using a common clinical test in patients with community-acquired pneumonia. Am J Emerg Med. 2014;32:700-4. 
16. Fine MJ, Auble TE, Yealy DM, Hanusa BH, Weissfeld LA, Singer DE, et al. A prediction rule to identify low-risk patients with community-acquired pneumonia. New Engl J Med. 1997;336:243-50.

17. Lim WS, van der Eerden MM, Laing R, Boersma WG, Karalus N, Town Gl, et al. Defining community acquired pneumonia severity on presentation to hospital: an international derivation and validation study. Thorax. 2003;58: 377-82.

18. Mandell LA, Wunderink RG, Anzueto A, Bartlett JG, Campbell GD, Dean NC, et al. Infectious Diseases Society of America/American Thoracic Society consensus guidelines on the management of community-acquired pneumonia in adults. Clin Infect Dis. 2007;44(Suppl 2):S27-72.

19. Charles PG, Wolfe R, Whitby M, Fine MJ, Fuller AJ, Stirling R, et al. SMARTCOP: a tool for predicting the need for intensive respiratory or vasopressor support in community-acquired pneumonia. Clin Infect Dis. 2008;47:375-84.

20. Jover F, Cuadrado JM, Andreu L, Martinez S, Canizares R, de la Tabla VO, et al. A comparative study of bacteremic and non-bacteremic pneumococcal pneumonia. Eur. J Int Med. 2008;19:15-21.

21. Amaro R, Liapikou A, Cilloniz C, Gabarrus A, Marco F, Sellares J, et al. Predictive and prognostic factors in patients with blood-culture-positive communityacquired pneumococcal pneumonia. Eur Respir J. 2016;48:797-807.

22. Kalin M, Ortqvist A, Almela M, Aufwerber E, Dwyer R, Henriques B, et al. Prospective study of prognostic factors in community-acquired bacteremic pneumococcal disease in 5 countries. J Infect Dis. 2000;182:840-7.

23. Plouffe JF, Breiman RF, Facklam RR. Bacteremia with Streptococcus Pneumoniae. Implications for therapy and prevention. Franklin County pneumonia study group. JAMA. 1996;275:194-8.

24. Marrie TJ, Low DE, De Carolis E, Canadian community-acquired pneumonia I. A comparison of bacteremic pneumococcal pneumonia with nonbacteremic community-acquired pneumonia of any etiology-results from a Canadian multicentre study. Can Respir J. 2003;10(7):368-74.

25. Tomczyk S, Bennett NM, Stoecker C, Gierke R, Moore MR, Whitney CG, et al. Use of 13-valent pneumococcal conjugate vaccine and 23-valent pneumococcal polysaccharide vaccine among adults aged $\geq 65$ years: recommendations of the advisory committee on immunization practices (ACIP). MMWR Morb Mortal Wkly Rep. 2014;63:822-5.

26. Musher DM, Rueda-Jaimes AM, Graviss EA, Rodriguez-Barradas MC. Effect of pneumococcal vaccination: a comparison of vaccination rates in patients with bacteremic and nonbacteremic pneumococcal pneumonia. Clin Infect Dis. 2006;43:1004-8.

27. Kolditz M, Schmitt J, Pletz MW, Tesch F. Impact of pneumococcal polysaccharide vaccine on incidence and mortality after pneumonia in adults aged $\geq 60$ years-a population-based retrospective cohort study. Clin Microbiol Infect. 2017; https://doi.org/10.1016/j.cmi.2017.08.010.

28. Ritchie ND, Mitchell TJ, Evans TJ. What is different about serotype 1 pneumococci? Future Microbiol. 2012;7:33-46.

29. Ceccato A, Torres A, Cilloniz C, Amaro R, Gabarrus A, Polverino E, et al. Invasive disease vs urinary antigen-confirmed pneumococcal communityacquired pneumonia. Chest. 2017;151:1311-9.

30. Goldwasser P, Feldman J. Association of serum albumin and mortality risk. J Clin Epidemiol. 1997;50:693-703.

31. Ranzani OT, Zampieri FG, Forte DN, Azevedo LC, Park M. C-reactive protein/ albumin ratio predicts 90-day mortality of septic patients. PLoS One. 2013; 8(3):e59321.

32. Musher DM, Rueda AM, Kaka AS, Mapara SM. The association between pneumococcal pneumonia and acute cardiac events. Clin Infect Dis. 2007: 45:158-65.

33. Horton JW, Maass DL, White J, Sanders B. Myocardial inflammatory responses to sepsis complicated by previous burn injury. Surg Infect. 2003;4:363-77.

34. Fillon S, Soulis K, Rajasekaran S, Benedict-Hamilton H, Radin JN, Orihuela CJ, et al. Platelet-activating factor receptor and innate immunity: uptake of gram-positive bacterial cell wall into host cells and cell-specific pathophysiology. J Immunol. 2006;177:6182-91.

35. Reyes LF, Restrepo MI, Hinojosa CA, Soni NJ, Anzueto A, Babu BL, et al. Severe pneumococcal pneumonia causes acute cardiac toxicity and subsequent cardiac remodeling. Am J Respir Crit Care Med. 2017;196:609-20.

36. Postma DF, van Werkhoven $\mathrm{CH}$, van Elden $\amalg$, Thijsen SF, Hoepelman Al, Kluytmans JA, et al. Antibiotic treatment strategies for community-acquired pneumonia in adults. New Engl J Med. 2015;372:1312-23.

37. Baddour LM, Yu VL, Klugman KP, Feldman C, Ortqvist A, Rello J, et al. Combination antibiotic therapy lowers mortality among severely ill patients with pneumococcal bacteremia. Am J Respir Crit Care Med. 2004;170:440-4.

\section{Submit your next manuscript to BioMed Central and we will help you at every step:}

- We accept pre-submission inquiries

- Our selector tool helps you to find the most relevant journal

- We provide round the clock customer support

- Convenient online submission

- Thorough peer review

- Inclusion in PubMed and all major indexing services

- Maximum visibility for your research

Submit your manuscript at www.biomedcentral.com/submit 